\title{
FLORA DE GRÃO-MOGOL, MINAS GERAIS: ONAGRACEAE ${ }^{1}$
}

\author{
ALEXANDRE A. S. GRILLO \& ANA MARIA GIULIETTI* \\ Departamento de Botânica, Instituto de Biociências, Universidade de São Paulo, \\ Caixa Postal 11461, 05422-970 - São Paulo, SP, Brasil \\ *Endereço atual: Departamento de Ciências Biológicas, Universidade Estadual de Feira de Santana, \\ km 3, BR 116, 44031-460 - Feira de Santana, BA, Brasil
}

Grillo, A.A.S \& Giulietti, A.M. 1998. Flora da Serra do Cipó, Minas Gerais: Onagraceae. Bol. Bot. Unit. São Paulo 17: 109-114.

Micheli, M. 1875. Onagraceae. In C.F.P. Martius \& A.G. Eichler (eds.) Flora brasiliensis. Frid. Fleischer. Leipzig, vol. 13, pars 2, p. 146-182, tab. 30-37.

Munz, P.A. 1947. Onagráceas. In F.C. Hoehne (ed.) Flora Brasílica 41 (1): 1-62; tab. 1-51.

Ramamoorthy, T.M. \& ZARdini, E.M. 1987. The systematics and evolution of Ludwigia (Sect. Myrtocarpus) sensu lato. Monogr. Syst. Bot. Missouri Bot. Gard. 19: 1-120.

\section{Ludwigia L.}

Ervas terrestres, aquáticas, subarbustos a arbustos. Folhas simples, alternas, sésseis a subsésseis. Flores bissexuadas, actinomorfas, em geral isoladas, axilares ou raramente racemosas, pediceladas ou sésseis; brácteas nas axilas das flores semelhantes às folhas em forma e tamanho; profilos 2, ao longo do pedicelo ou na base do hipanto, decíduos; sépalas 4(5), livres, valvares; pétalas 4(5), livres, decíduas, amarelas; disco nectarífero cônico ou piramidado, nectários cobertos por indumento de tricomas alvos: androceu diplostêmone; estames muitas vezes desiguais em forma e tamanho; ovário sincárpico, ínfero a semi-ínfero, 4-carpelar, geralmente cônico ou anguloso, pluriovulado; placentação axial; estigma, globoso a subgloboso, papiloso e coberto por secreções. Fruto cápsula obcônica, obpiramidal ou clavada, deiscente ou indeiscente; sementes geralmente livres ou mergulhadas em endocarpo carnoso persistente, uni a plurisseriadas.

1. Flores sésseis a subsésseis, pedicelos 1-2 mm compr.; rafe destacada, maior ou igual ao comprimento e largura do corpo da semente L. octovalvis

1'. Flores pediceladas, pedicelos $0,7-4 \mathrm{~cm}$ compr., rafe muito estreita, 1/4-1/6 da largura do corpo da semente.

2. Folhas com menos de 2 cm compr., nervura submarginal inconspícua; disco achatado, 0,8-1,1 mm alt. L. myrtifolia

2'. Folhas com mais de $2,5 \mathrm{~cm}$ compr., nervura submarginal bastante evidente; disco alto, 2-4 $\mathrm{mm}$ alt.

3. Profilos reduzidos, ca. $2 \mathrm{~mm}$ compr., estames de alturas desiguais

L. nervosa

3'. Profilos desenvolvidos, 0,7-1,2cm compr.; estames de alturas subiguais L. laruotteana

1.1. Ludwigia laruotteana (Cambess.) Hara, J. Jap. Bot. 28: 292. 1953.

Subarbusto a arbusto 1-4 $\mathrm{m}$ alt., ramos glabros a pubescentes, os novos angulosos. Folhas cartáceas, pubérulas, elípticas a oblongo-elípticas, $8-13 \mathrm{~cm}$ compr., 3-5 cm larg., ápice mucronado, base aguda decurrente no pecíolo, margem inteira, ciliada. Pedicelos $1,5-3 \mathrm{~cm}$ compr., até $4 \mathrm{~cm}$ compr. na frutificação, pubescentes; profilos 0,7-1,2 cm compr., 2-3 mm larg., lanceolados a

\footnotetext{
' Trabalho realizado conforme o planejamento apresentado por Pirani et al. (2003). Bol. Bot. Univ. São Paulo 21(1): 1-24.
} 
oval-lanceolados, inseridos na base do ovário, muitas vezes persistentes no fruto. Flores 4-meras, isoladas, axilares a reunidas em racemos; sépalas 1,2-1,5 cm compr., 5-8 mm larg., lanceoladas, acuminadas, 5-9- nervadas, pilosas a glabras, margens ligeiramente sinuosas; pétalas 2,2-2,8 cm compr., 2,2-3,2 cm larg., obovais a orbiculares; estames 8, alturas subiguais, filetes achatados $4-5 \mathrm{~mm}$ compr., anteras 3-4 mm compr. oblongas; ovário 0,7-1,5 cm compr., obpiramidal, 4-anguloso, pubescente: disco elevado, cônico, $2-4 \mathrm{~mm}$ alt.; estilete $2-4 \mathrm{~mm}$ compr., cilíndrico, estigma ca. $2 \mathrm{~mm}$ compr., subgloboso. Cápsulas 1,4-1,8 cm compr., obpiramidais, 4-angulosas, pubescentes; sementes ca. 1,4 $\mathrm{mm}$ compr., 0,6 mm larg., elipsóide-oblongas, amarelo-sulfurosas, transversalmente estriadas, rafes muito estreitas, até $1 \mathrm{~mm}$ larg. (Fig. 1. $\mathrm{R}-\mathrm{X}$ )

Cordeiro et al. CFCR 114949 (SPF); Mello-Silua EO Pirani CFCR 10689(MO, SPF); Simão-Bianchini et al. CFCR 13153 (MO, SPF).

Restrita às regiōes Centro-Oeste e Sudeste e Sul do Brasil, em vários habitats, como brejos e beira de rios. É facilmente reconhecível pelo porte arbustivo bastante robusto em relação às demais espécies encontradas na área. A floração ocorre de janeiro a julho, principalmente de fevereiro a abril.

Nome vulgar: cruz-de-malta.

1.2. Ludwigia myrtifolia (Cambess.) Hara, J. Jap. Bot. 28: 293. 1953.

Ervas, subarbustos a arbustos, 0,7-3 $\mathrm{m}$ alt.; ramos pilosos a glabrescentes. Folhas sésseis a subsésseis (pecíolos ca. $1 \mathrm{~mm}$ compr.), cartáceas, estreitamente lanceoladas a lanceolado-oblongas, ou ainda elípticas, 2-2,7 cm compr., 3-7 mm larg., ápice acuminado, base obtusa a arredondada, margem inteira ou ligeiramente sinuosa, nervura submarginal inconspícua; estípulas 2$6 \mathrm{~mm}$ compr., decíduas. Pedicelos $0,9-1,5 \mathrm{~cm}$ compr. na antese, até $2,5 \mathrm{~cm}$ compr. na frutificação, cilíndricos, pubescentes a glabros; profilos $4-6 \mathrm{~mm}$ compr., ca. 1 mm larg., linear-lanceolados a lanceolados, acuminados a agudos, pubescentes a glabros, na base do ovário ou no meio do pedicelo, decíduos. Flores 4-meras, isoladas, axilares; sépalas 0,8-1 cm compr., 2-5 mm larg., oval-lanceoladas, acuminadas, pilosas a glabras; pétalas $1-2 \mathrm{~cm}$ compr., $1-2 \mathrm{~cm}$ larg., cuneiformes, orbiculares a obovais; estames 8, alturas desiguais, 1,3-3,2 cm compr., anteras oblongas; ovário 3-8 cm compr., 2-5 mm larg., 4-anguloso, piloso a glabro, disco achatado $0,8-1,1 \mathrm{~mm}$ alt. estilete, 2-3 mm compr., estigma 2-2,2 mm compr., globoso ou subgloboso. Cápsulas 0,5-1,5 cm compr., 4-7 cm larg., obpiramidais, podendo tornar-se obcônicas com a maturidade, base abruptamente estreitada, 4-angulosa; sementes 0,9-1,1 mm compr., ca. 0,5 mm larg., ovaiselípticas, amarelas-creme, rafe estreita. (Fig. 1. G-L)

\section{Assis et al. CFCR 11608 (SPF).}

Restrita a Minas Gerais, principalmente nas cercanias de Diamantina e Serra do Cipó, ocupando diversos habitats, tais como brejos, locais úmidos e alagados e ao longo das margens dos rios, sendo mais abundante na estação chuvosa. De acordo com Ramamoorthy \& Zardini (1987), plantas com características intermediárias entre L. myrtifolia e L. nervosa (Poir.) Hara são freqüentes; os espécimes de Grão-Mogol apresentaram algumas características intermediárias, porém estas não chegaram a interferir na identificação dos mesmos. Variações quantitativas relacionadas ao indumento foram observadas em flores de um mesmo indivíduo, mas podem estar relacionadas ao grau de maturidade das mesmas. A floração ocorre de fevereiro a abril.

Nome vulgar: cruz-de-malta.

1.3. Luduigia neruosa (Poir.) Hara, J. Jap. Bot. 28: 293. 1953.

Subarbustos a arbustos 1,5-4 $\mathrm{m}$ alt.; ramos pilosos a glabros. Folhas sésseis a subsésseis (pecíolos 1-2 mm compr.), cartáceas, glabras a pilosas, lanceoladas a ovallanceoladas, 4-7 cm compr., 1,5-2,5 cm larg., ápice agudo, base arredondada a obtusa, margem inteira a ligeiramente sinuosa, nervura submarginal bastante destacada. Pedicelos 0,7-2,5 cm compr. na antese, até $4 \mathrm{~cm}$ compr. na frutificação, cilíndricos a angulosos, pilosos a glabros; profilos 2-3 mm compr., lineares, glabros a pilosos, entre a metade superior do pedicelo e a base do ovário, decíduos. Flores 4-meras, isoladas, axilares; sépalas 0,8-1,2 cm compr., 3-4 mm larg., acuminadas a agudas, geralmente 3-nervadas, pilosas a glabras; pétalas $1,4-2 \mathrm{~cm}$ compr., 1,3-2,2 cm larg., orbiculares a cuneiformes; estames 8 , alturas desiguais, filetes $1-2 \mathrm{~mm}$ compr., anteras oblongas 3-6 mm compr.; ovário 0,5-1,2 cm compr., 4anguloso, obcônico, piloso a glabro; disco elevado, cônico, 2-4 mm alt., estilete 1-2 mm compr., estigma ca. 1 mm compr., globoso. Cápsulas 1-1,5 cm compr., 5-8 mm compr., estreitamente obcônicas a subcilíndricas, 4-angulosas, hirsutas a glabras; sementes 1,1-1,3 mm compr., ca. $0,5 \mathrm{~mm}$ larg., oblongas, amarelo-escuras, estriadas transversalmente, rafe muito estreita, até $1 \mathrm{~mm}$ larg. (Fig. 1. M-Q)

Cordeiro Eै Mello-Silva CFCR 10115 (MO, SPF); Harley et al. 25104 (BOL, K, SPF); Oliveira et al. CFCR 13155 (MO, SPF); Zappi et al. CFCR 11981 (MO, SPF). 
Flora de Grão-Mogol, Minas Gerais: Onagraceae
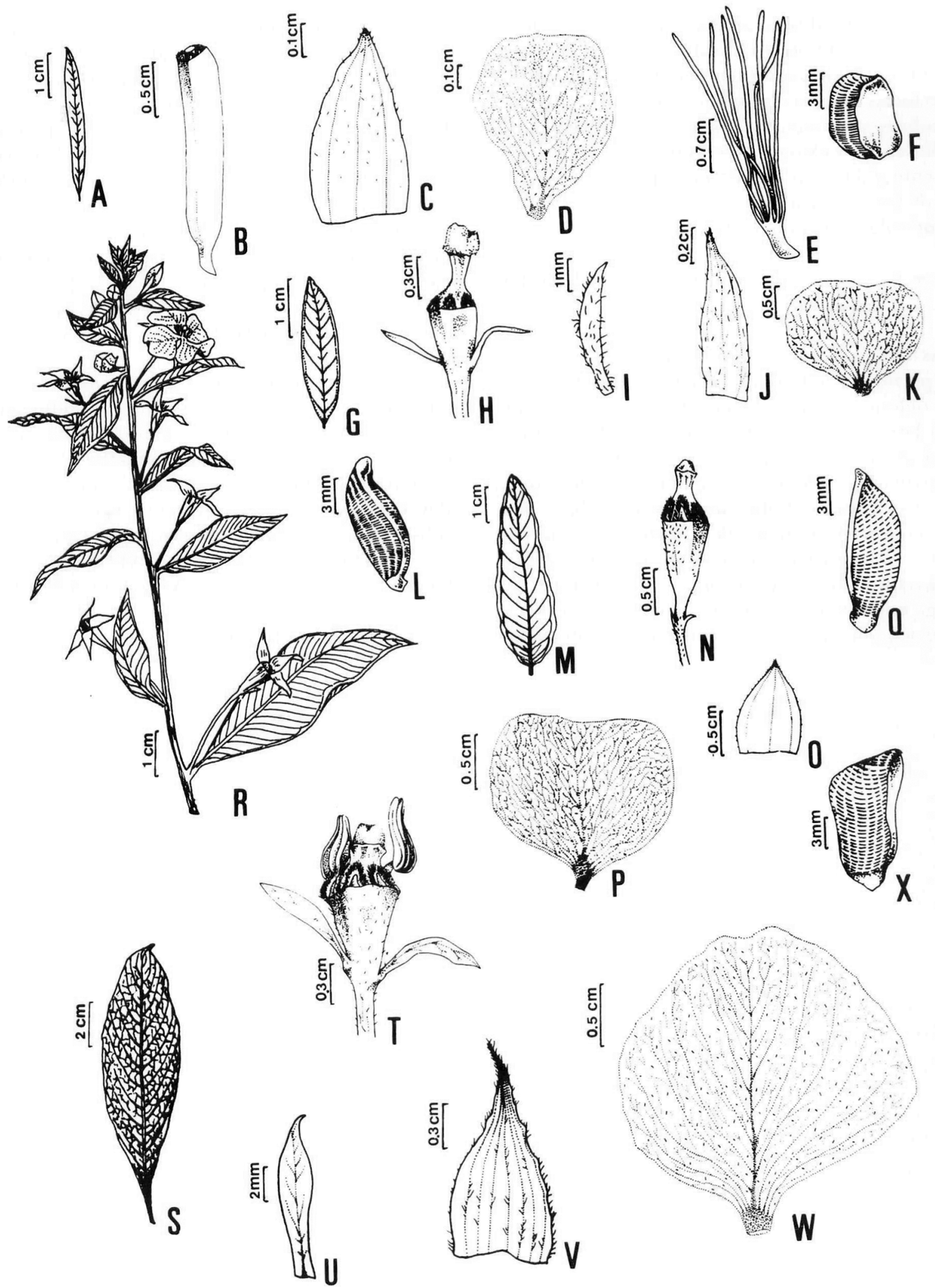

Fig. 1. ONAGRACEAE. Ludtuigin. A-F. L. oc:tovalvis: A. Folha; B- Disco nectarífero; C. Sépala; D. Pétala; E. Fruto maduro aberto; F. Semente. GL. L. myrtifolia: G. Folha; H. Disco nectarífero, profilos, gineceu e estame; I. Profilo; J. Sépala; K. Pétala; L. Semente. M-Q. L. nervosa: M. Folha; N. Disco nectarífero, profilos e gineceu; O. Sépala; P. Pétala; Q. Semente; R-X. L. laruolleana: R. Hábito; S. Folha; T. Disco nectarífero, profilos, gineceu e 2 estames; U. Profilo; V. Sépala, W. Pétala; X. Semente. 
Do sudeste do México ao Paraguai, e do Nordeste, Sudeste e Centro-Oeste do Brasil, desde o nível do mar até alturas superiores a $1000 \mathrm{~m}$, em vários habitats, incluindo locais úmidos e alagadiços, em solos pedregosos e pobres, geralmente encharcados. Os indivíduos coletados em Grão-Mogol observou-se indivíduos completamente glabros a outros bastante pilosos. A floração ocorre de fevereiro a abril.

Nome vulgar: cruz-de-malta.

1.4. Ludwigia octovalvis (Jacq.) Raven, Kew Bull. 15: 476. 1962.

Ervas 0,3-2 $\mathrm{m}$ alt., ramos glabros. Folhas sésseis a subsésseis (pecíolo 1-2 mm compr.), membranáceas, glabrescentes, oblongas a linear-lanceoladas, $2-7 \mathrm{~cm}$ compr., 2-5 mm larg., ápice acuminado a agudo, base aguda, margem inteira, nervura submarginal inconspícua recurvadas, decíduas. Pedicelos 1-2 mm compr. na antese, pouco mais longos na frutificação, glabros a pubescentes; profilos inconspícuos (menos de $0,8 \mathrm{~mm}$ compr.), na parte superior do pedicelo, triangulares, decíduos. Flores isoladas, axilares, 4-meras; sépalas 4-8 $\mathrm{mm}$ compr., 2-5 mm larg., estreitas a largamente ovais, obtusas a abruptamente acuminadas, glabras a subglabras, 3-nervadas; pétalas 0,6-1 cm compr., 0,6-1 cm larg., cuneiformes, orbiculares a obovais; estames 8 , alturas desiguais, glabros a pubescentes, filetes $1,5-3,5 \mathrm{~cm}$ compr, anteras oblongas; ovário 1-1,5 cm compr., clavado-cilíndrico, 4-anguloso; disco achatado, 0,8-1,1 mm alt.; estigma 1,5-3 $\mathrm{mm}$ compr., subgloboso ou globoso, estilete $1-3 \mathrm{~mm}$ compr., espesso. Cápsulas 2-4 cm compr., cilíndricas a clavadocilindrícas, 4-angulosas; sementes ca. 0,6 mm compr., $0,3 \mathrm{~mm}$ larg., arredondadas, castanhas, transversalmente estriadas, livres, rafes destacadas, ca. $0,7 \mathrm{~mm}$ compr., ca. $0,4 \mathrm{~mm}$ larg. (Fig. 1. A-F)

Pirani et al. CFCR 11319 (SPF).

Ampla distribuição geográfica, embora seja mais comum nas Américas, ocorrendo em regiões alagadas, brejos ou solos pedregosos e úmidos. Raven (1963) reconhece duas subspécies; em Grão-Mogol foi coletado apenas espécime pertencente a $L$. octovalvis (Jacq.) Raven subsp. octovalvis. A outra subspécie, $L$. octovalvis subsp. sessiliflora (Mich.) Raven provavelmente ocorre na área, já que é comum a ocorrência de populaçōes mistas das duas subespécies. A floração ocorre entre os meses de janeiro a maio.

Nome vulgar: cruz-de-malta. 